\title{
RABINDRANATH TAGORE Y SUS IDEALES SOBRE LA EDUCACIÓN
}

\author{
Sol Argüello Scriba \\ Profesora de la Escuela de Filología, Lingüística y Literatura \\ Recibido 21-X-2003 • Aceptado 11-XI-2003 \\ Dedicado al Hogar Calasanz \\ Children run out of the Temple and play in the dust. \\ God watches their games and forget the priest. De "La escuela del poeta". \\ (Los niños abandonan corriendo el templo y juegan en el polvo. \\ Dios contempla sus juegos y olvida al sacerdote.)
}

\begin{abstract}
Resumen: Rabindranath Tagore, como se le conoce en occidente, fue el primer escritor asiático que obtiene el premio Nobel en Literatura, en 1913; pero su capacidad creadora no se expresó, únicamente, como literato, sino que fue artista y un gran filósofo sobre la educación y este pensamiento lo llevó a la acción concreta cuando fundó la escuela llamada en sánscrito: Shantiniketan y que luego se convirtió en la universidad Vishva Bharathi.
\end{abstract}

Palabras clave: Educación, Literatura, Niño (a), Escuela, Filosofía.

\begin{abstract}
Rabindranath Tagore, as he is kown in the Western world, was the first Asian writer to win the Nobel Prize for literature in 1913; his creative ability was not only expressed in literature: he was also an artist and a great philosopher of education. His particular thoughts led him to concrete actions in founding the Shantiniketan School, which later on became the Visha Bharathi university.
\end{abstract}

Key words: Education, Literature, Childhood, School, Philosophy.

\section{Introducción}

Hemos decidido transcribir este poema de Rabindranath Tagore, epígrafe de su ensayo titulado "La escuela del poeta", porque resume los ideales sobre la educación de un hombre profundamente religioso y humanista, cualidades que se observan tanto en su obra literaria como en su servicio a la sociedad, sobre todo cuando se propuso fundar una escuela que luego se convirtió en universidad. En el poema también podemos intuir el valor que le dio a la niñez en sus diferentes etapas ya fuese niña o niño; y así planteó una educación que le diera un lugar apropiado a la persona, una filosofía educativa que trascendió la India misma.

Así, en este pequeño estudio, se pretende presentar a Tagore como el educador, una de las múltiples facetas de su personalidad; puesto que, aparte de esta vocación, sus contemporáneos lo conocieron como un hombre renacentista moderno debido a sus múltiples actividades e intereses 
que nombraremos más adelante. Aunque es difícil dejar de lado su actividad más importante, la de "poeta" (como él mismo se autodenominaba), por ser la poesía una constante en toda su creación, ya fuese en sus ensayos, obras teatrales o narrativa, puesto que incursionó en todos los géneros literarios.

Sin embargo y a pesar de que al estudiar su obra en general no nos podemos desligar de su arte poético, es necesario aclarar que solamente hemos consultado, para el presente estudio, sus ensayos sobre la educación, traducidos del bengalí al inglés y de este idioma al español. Estos nos hablan del pensamiento filosófico del autor, publicados en inglés y no en bengalí1, entre ellos, se encuentra "El maestro" una conferencia impartida, en 1930, que pertenece al ciclo de Conferencias Hibbert que impartió Tagore en la Universidad de Oxford en el Manchester College, Inglaterra, y que fueron publicadas en el libro $L a$ religión del hombre.

También hemos consultado la colección de ensayos Towards Universal Man (Hacia el hombre universal), publicados en 1961, debido a la conmemoración mundial del centenario del nacimiento de Tagore, con temas que versan sobre los problemas sociales contemporáneos, entre ellos, los que se refieren a temas sobre la educación, titulados "Las vicisitudes de la educación", "El problema de la educación", "La unidad de la educación", "Universidad hindú", "La escuela del poeta", que por su importancia se repitió en esta publicación.

Es necesario aclarar, que para el presente trabajo no se ha estudiado su creación poética en la que la niñez es su motivo principal, como "La luna nueva", lo mismo muchos otros poemas y cuentos, puesto que en ellos no se pueden apreciar tan claramente sus ideales educativos.

Como podemos observar, el tema de la educación siempre constituyó una gran preocupación para Tagore, varios de esos ensayos son producto de su experiencia como educador y fundador de su escuela, a la que dedicó no solo tiempo sino parte de su fortuna personal. También presentaremos la educación que el autor recibió y cómo su experiencia personal influyó en su filosofía educativa, la escuela, la universidad, la educación en la India y sus cambios en tiempos del autor.

\section{Rabindranath Tagore, la persona y su mundo}

En este apartado nos hemos concentrado en Tagore como el educador y cuáles fueron su ambiente familiar, el entorno social, cultural y político que formaron su personalidad y lo llevaron a fundar una escuela; en fin, a plantear una filosofía sobre la educación de los jóvenes, que podemos trasladar al mundo moderno y encontrarla vigente. Dejaremos de lado su versatilidad y capacidades tan grandes que lo hicieron destacarse como poeta, dramaturgo, novelista, actor, compositor, filósofo, patriota, reformador social, humanista, pintor y profeta; pero sobre todo, un ser humano profundamente religioso.

La vida de Rabindranath Takhur, conocido como Tagore fuera de la India como producto de la pronunciación en inglés de su apellido, transcurrió en una época de grandes cambios en la vida cultural, literaria y política de una India bajo el dominio inglés, aspectos que serán decisivos en su educación y forma de vida.

El poeta nace en el seno de una familia numerosa: era el décimo cuarto de los hijos de Devendranath ${ }^{2}$, en Calcuta, región de Bengala, el 6 de mayo de 1861. Los Tagore constituían una familia con un reconocido status económico y social; y especialmente favorecida con el don de las letras. Varios de sus hermanos se inclinaron por las artes también y tuvieron una reconocida participación en el mundo artístico e intelectual de Calcuta y de la India. Entre los afamados escritores indios del siglo 
XIX, están sus hermanos mayores: Dwijendranath Tagore (1840-1926), el hermano mayor de Rabindranath, era un hombre de genio y de múltiples intereses, magnífico dibujante, se interesaba en la música, la filosofía, las matemáticas, y podía escribir excelente prosa y poesía, además de componer canciones patrióticas y religiosas. Uno de sus logros fue el utilizar algunos metros difíciles de la poesía sánscrita en la versificación bengalí.

En la obra "Recuerdos" de Rabindranath cuenta cómo estuvo rodeado en su hogar de una atmósfera intelectual y artística poco común en la vida de un escritor. Menciona que en su hogar, el padre promovía la presencia de musulmanes, cristianos y otras denominaciones religiosas lo que le dio una formación universal en las principales religiones que estaban presentes en Calcuta; también se daba un profundo interés de sus hermanos mayores en asuntos literarios y de cómo esto le provocó su vocación de escritor. Se celebraban a menudo veladas familiares artísticas en las que los hermanos y él participaban activamente. Jyotirindranath, otro de sus hermanos, fue uno de los hombres mejor dotados de su tiempo: tocaba el violín y el piano, dibujaba bien y escribía en una prosa elegante. Compuso obras de teatro entre las cuales vale la pena mencionar "Puruvikram" (El poder de Puru, 1875), en la cual podemos ver el creciente nacionalismo de aquellos días, al cual estaba asociada la familia Tagore. Se distinguió por ser un gran traductor al bengalí casi todas las obras de teatro sánscritas importantes, y también de obras teatrales del inglés y del francés como el "Julio César” de Shakespeare, y algunas obras de Molière. Dio a conocer a los lectores bengalíes obras de algunos de los mejores escritores franceses del siglo XIX.

Como era una familia de tanta afición por la literatura, encontramos también a una de las hermanas mayores de Rabindranath, Svarna Kumari Devi (1855-1932), fue la primera y más connotada escritora de
Bengala. Escribió novelas, cuentos, poesía y drama. En sus obras presenta algunos de los problemas de la clase media culta de Calcuta. Editó la revista mensual "Bharati" por varios años, la cual había sido comenzada por sus hermanos en 1877, y a la que también Rabindranath prestó su colaboración.

Eran adinerados, pero sobresalieron por su magnífica cultura y educación; provenían de casta brahmana ${ }^{3}$ y se distinguieron por ser patriotas, que se reconocía por el profundo orgullo que sentían por la diversidad de su cultura india. Es necesario resaltar que eran de ideas avanzadas y pertenecieron a los grupos de indios que promovieron las reformas religiosas y sociales de Bengala, por lo tanto rechazaban la estrecha ortodoxia.

En este ambiente familiar tan especial, se llega a la conclusión de que la educación de Rabindranath fue muy particular, que junto con la ciudad de Calcuta, le proporcionaron elementos de gran valor en su formación. Citamos la ciudad de Calcuta, puesto que es aquí donde surge el Renacimiento Cultural Bengalí, en el siglo XIX, base de las reformas sociales, religiosas y políticas más importantes de la India, y que fortalecerá los movimientos independentistas que culminarán con la política de no cooperación y de no violencia de Gandhi, cuyos resultados todos conocemos.

Este movimiento cultural surgió como respuesta a la imposición cultural europea, y su estandarte de lucha fue la difusión de pensamientos en lengua bengalí, es así como aparecen varios periódicos y valiosas obras literarias. Al haberse convertido el inglés, en toda la India, en el siglo XIX, no solo en el idioma de la administración, sino que había sido impuesto como la lengua oficial de enseñanza, así en las escuelas se debía aprender como si fuese la lengua materna, lo que motivó a algunos escritores indios a escribir en inglés y a imitar modelos europeos muy alejados de su realidad, y dejando de lado sus ricas lenguas maternas ${ }^{4}$ Es así como surge la 
necesidad de autoafirmación, de escribir en bengalí y aparecen grandes escritores, tanto hombres como mujeres. Pero será Tagore quien lleve a la culminación este movimiento literario con sus famosas obras literarias. Es necesario aclarar que luego de la aparición de este movimiento de renacimiento cultural en Bengala, pronto surgirán movimientos similares en toda la India, y encontraremos connotados escritores indios, entre ellos y como hemos citado anteriormente a algunos de sus hermanos mayores que escribieron en sus lenguas maternas.

Hay un tercer aspecto que Rabindranath mismo nos cuenta y es la presencia de los baüls en la región de Bengala. Poetas libres que buscan en lo cotidiano, en la poesía y la música una expresión de devoción ${ }^{5}$ y amor a la divinidad particular, en ellos hay una especie de sincretismo religioso, aunque es mucho más compleja la explicación sobre los baüls, se puede decir que, existen todavía hoy en la citada región y son escuchados por la gente como cantautores religiosos y populares al mismo tiempo. Tagore se refiere a ellos de la siguiente manera: Baül significa loco, de Bayu (sánscrito vayu), en su sentido de corriente nerviosa, y ha venido a ser el apelativo de una secta formada por individuos que no se conforman con los usos sociales establecidos 6 .

A lo que agrega más adelante:

Aunque los baüls cuentan entre sus secuaces variedad de sectas y castas, hindúes como musulmanas, procedentes en su mayoría de las más bajas capas sociales, niéganse terminantemente a dar más pormenores de sí mismos a quienes interrogan, limitándose a decir que son baüls. No reconocen ninguna formalidad social ni religiosa; pero se complacen en el siempre cambiante juego de la vida, que no se deja expresar en meras palabras, pero del que algo cabe apresar en el canto, en virtud del inefable medio del ritmo y el tono. Sus cantos se van transmitiendo del Maestro al discípulo, el cual, cuando está capacitado para ello, añade otros cantos de su propia cosecha; pero, según ya dijimos, jamás esos cantos se recogen en forma de libro. ${ }^{7}$
Así Rabindranath Tagore siendo niño escuchaba a estos cantautores populares, cuya religiosidad, aún hoy, no se restringue a los templos, aspecto muy importante del hinduísmo; otra característica de los baüls es que muchos adeptos provienen de las castas más bajas, también hay musulmanes. Tagore, en parte, se inspiró en ellos y admiraba su libertad y religiosidad. De esta manera vemos en él ambos aspectos, por un lado la forma de vida de los baüls unida a la forma de vida familiar poco conservadora y ortodoxa que lo acompañará a lo largo de su existencia. Rabindranath, por tales razones, abogará porque los niños entren a su escuela sin tomar en cuenta la casta o la religión a la que pertenecen; lo que será muy novedoso.

Por otro lado, hay que tener en cuenta que la región de Bengala era una zona de gran desarrollo comercial en la India y es la que fuertemente recibe el impacto inglés. La presencia europea en el Asia se debe a la industrialización europea y a la necesidad de búsqueda de mercados; así la llegada inglesa provocará profundos cambios en la sociedad india, lo mismo que la acentuación de ortodoxias que se habían venido gestado con una anterior invasión, la musulmana. Los ingleses no se asimilan a la población india, y esta considerará el gobierno inglés como impuro. Aunque es bueno resaltar, que entre los indios hubo grandes pensadores que buscaron cambios positivos y gestaron las reformas sociales en la India. Entre estas mentes privilegiadas encontramos a Tagore, quien recibe en su hogar los principios de respecto por los "otros", un pensamiento de tolerancia y aceptación de las diferentes corrientes religiosas y como ya leímos anteriormente, el estudio de la música y las artes en general. Este fue el medio espiritual en que el joven Tagore aprendió; puesto que su educación formal duró solo cinco años, con los sacerdotes católicos escoceses, quienes se dieron por vencidos y le informaron al padre de 
Tagore que él no iba a ser capaz de aprender y así devolvieron al niño Rabindranath a su casa. A partir de este momento, su padre le encarga la instrucción a sus hermanos mayores. En esta educación, se ve, no solo la naturaleza especial ${ }^{8}$ con que nació Rabindranath, sino cómo era un ambiente familiar propicio para hacer de él un gran creador.

A los ocho años publica su primer poema y de ahí en adelante no parará de escribir; se dice que para reescribir su obra literaria se tardaría 50 años, haciéndolo durante todos los días. Su lengua materna fue el bengalí, en la que compuso más de 2000 canciones, entre ellas, los dos himnos nacionales, el de la India y el de Bangladesh. A los 17 años fue enviado a Inglaterra a estudiar Derecho, carrera que no concluyó porque debió regresar a su patria y administrar las tierras de la familia; mucha de su riqueza se había perdido y por tanto aunque aún tenían cierta holgura económica, nunca hubo ostentación en su familia y Tagore siempre vistió de algodón, el vestido de los pobres, inclusive en invierno y fue parco hasta en su alimentación.

Prolífico escritor, y él mismo tradujo varias de sus obras al inglés, lo que le permitió ser leído en occidente y convertirse en el primer asiático que recibió el premio Nobel en Literatura, en 1913, con la obra "Gitanjali” (Canción al Señor). Incursionó en todos los géneros literarios y escribió y compuso la música de sus canciones; aún hoy, hay artistas que se especializan en ser intérpretes de su música.

Posteriormente, al cumplir 40 años funda su escuela, a los 70, comienza a pintar formalmente, expone sus pinturas en Europa y a los 80, muere el 6 de mayo de 1941. Es interesante recordar que unos meses antes de su deceso en el 14 de abril, cuando el mundo entero se debate en la una de las peores guerras que han existido en la humanidad, transmite un mensaje esperanzador al mundo, titulado: "La crisis de la civilización”, con las siguientes palabras:
Aún así, no cometeré el grave pecado de perder mi fe en el hombre, aceptando como definitiva la presente derrota. Miraré hacia el futuro con la esperanza de un renacer histórico cuando haya pasado este cataclismo y el cielo quede limpio de pasiones. Puede que un amanecer nuevo aparezca por el horizonte, viniendo del este, por donde sale el sol; y entonces el hombre volverá a recorrer invicto, desafiando todos los obstáculos, el camino de la reconquista de su herencia perdida.

En este ensayo final, se entiende su deseo de que el hombre siempre es capaz de hacer de la existencia algo valioso y que será posible el entendimiento entre occidente y oriente en un solo lenguaje, el de la concordia.

\section{Sus ideales sobre la educación y la creación de una nueva escuela}

En 1901, su pensamiento alrededor de sus ideales educativos se ven puestos en la práctica cuando Rabindranath decide fundar su escuela, en Bolpur, aldea rural de Bengala, en la que su padre tenía propiedades y una casa de campo. La llamó Shantiniketan palabra sánscrita que quiere decir: Morada de Paz; y muchos años después, en 1919, se convierte en Vishva Bharathi, la universidad internacional. Posteriormente, en 1922, funda un instituto rural para los artesanos y artistas llamado Shriniketan. Así Bolpur sigue siendo, hoy, un lugar de encuentro de artistas e intelectuales del mundo, no solo de la India.

Estos centros educativos fueron fundados como respuesta al impacto provocado por la llegada inglesa a la cultura india, y logró despertar un gran interés en algunos indios que quisieron renovar y modernizar la educación india, sobre todo en Calcuta, porque precisamente, es en esta ciudad donde surgen los primeros cambios que los ingleses imponen junto con la administración. También estos centros educativos y su filosofía educativa lograron despertar en occidente un creciente interés. 
A comienzos del siglo XIX, los indios de Calcuta, con el apoyo de algunos ingleses, buscan introducir la educación occidental. En 1817, se fundó el "Colegio Hindú”, y allí Henry Derozio (1809-1831) fue uno de los grandes maestros ingleses que llegó a tener una gran influencia en sus discípulos. Había leído bastante de la filosofía liberal europea y transmitió sus ideas occidentales y sus actitudes a los estudiantes. Muchos jóvenes bengalíes brillantes fueron a ese colegio a aprender los nuevos conocimientos llegados de Occidente. Este colegio recibió un gran apoyo de Ram Mohum Roy, fundador de la secta Brahmo Samaj, quien estaba a favor de dar a conocer las ciencias occidentales; él favoreció la introducción de esta educación inglesa, aunque eso no implicaba su renuncia a la tradición india. Así se inicia una nueva de la educación india, que afianzaba el dominio cultural inglés, sobre todo, en la clase culta de Bengala.

Esto significaba que, durante la primera mitad del siglo XIX, la educación en la India se abrió a posibilidades que no habían sido imaginadas, a pesar de que la educación tradicional nunca fue deshechada; en lo que sí influenció fue que se abandonaran tradiciones religiosas innecesarias, que se habían adherido con el paso de los siglos y que implicaban una dolorosa ortodoxia. Con estos jóvenes, formados en esta educación a la occidental, surge el deseo de promover las grandes reformas sociales y políticas indias que culminarán, posteriormente, con el movimiento independentista indio.

Rabindranath Tagore nace en la segunda mitad del siglo XIX, cuando ya se había consolidado parte de este esfuerzo y en una familia que participaba de estos ideales en la educación, en medio de mentes brillantes que entendían que las raíces culturales debían ser mantenidas, sin limitarse a condiciones de las que no había por qué enorgullecerse. Así Tagore fue enviado a la escuela de sacerdotes escoceses católicos, durante cinco años, y en los que afirma no fue feliz, como dice en este texto:
Según costumbre, fui enviado a la escuela; es posible que a causa de mi inadaptación, mis sufrimientos fueran aún mayores que los de otros niños. En mi ser vivía una parte no civilizada, sedienta de color, de música y de movimiento. Nuestra educación urbana no tuvo en cuenta este hecho tan vital. La distribución de sus valores estaba ya organizada. En el hombre, lo civilizado y lo no civilizado deben corresponder en proporción, a la superficie que ocupan la tierra y el agua en nuestro Globo; mas la escuela se proponía como único objetivo la conversión de los no civilizados.

Más adelante agrega:

Pronto triunfó mi parte incivilizada, alejándome del colegio cuando apenas contaba trece años. (La escuela del poeta, pág. 281).

El resultado de esa experiencia, en esa institución educativa, fue tal que el niño fue devuelto a la casa, y como se lee en el apartado anterior, su instrucción le fue dada por sus hermanos mayores y sin ninguna oposición de parte suya.

Y en el párrafo anterior el autor expone, claramente, una de sus inquietudes más grandes, la ausencia del contacto con la naturaleza, que aún hoy, se observa como uno de los serios problemas que han tenido los sistemas educativos, en los que se busca educar al joven para "civilizarlo", pero olvidando la individualidad, la espiritualidad y sus orígenes. Alejándolo del contacto con la naturaleza y de esa vivencia. Y como respuesta Tagore buscará mantener a sus niños en contacto con la naturaleza.

Si el joven Tagore aprendió tanto las letras como las artes en casa y todos los conocimientos sobre la ciencia moderna que hasta el momento se conocía. Su educación fue así equilibrada e integral, lo mismo querrá para su escuela. Esta será el pilar principal sobre el que se fundamente su ideal educativo en ella, donde el conocimiento se aprenderá sobre las bases de la libertad de culto religioso, de pensamiento o filosofía tomando en cuenta la diversidad cultural de la India.

En su escuela, pero todavía más en su universidad, buscó establecer un diálogo 
entre Asia y Occidente y encontrar puntos de convergencia, para lo cual todas las materias impartidas tendrían que servir para este fin. Por eso el autor buscó hombres y medios occidentales, no solo indios, para introducir las materias que formaran el carácter del joven, a lo que Tagore agrega lo siguiente:

Necesitaba del genio occidental para dar a mi ideal educativo la fuerza de la realidad y lograr un fin determinado y práctico. (La escuela del poeta, pag. 284).

Es así que vamos observando en el autor un pensamiento universal y humanista, donde es válido darle una dimensión de justicia y de amor al niño y su derecho a la infancia feliz, una posición de importancia a la mujer, al dolor de los seres humanos o la alegría de vivir; y que también son motivos presentes en su literatura.

Arraigado profundamente su pensamiento en la filosofía de las Upanishadas ${ }^{9}$, cuyos maestros o rishis (videntes) habían vivido en los ashramas en los bosques, donde no había paredes, ni aulas que separasen al hombre de la naturaleza, pensamiento que había dejado una gran huella en la civilización india. Estos sabios habían meditado en pleno contacto con la naturaleza y habían transmitido sus enseñanzas allí, sin la sensación de que estaban enjaulados.

Eran filósofos creadores de un nuevo pensamiento, que se separaba de la concepción sacerdotal y tradicional del cosmos que, no necesariamente, estaba opuesta; pero su actitud implicaba una nueva concepción de eternidad y de comunión del alma humana con el alma universal siendo ambas una sola, eternas, intemporales e imperecederas. El maestro de las Upanishadas tenía como objetivo enseñar esto, hacer comprender a los alumnos que también eran seres espirituales, que traducido a términos occidentales: hacer que el alumno descubriese su naturaleza divina, su atman (alma) que es parte de su Creador o Ser Supremo (brahman). Era y es, en fin, una filosofía metafísica de la vida y que no es excluyente del ritual religioso personal o grupal védico. Tagore lo resume en los siguientes textos del ensayo "La escuela del poeta":

Los más grandes maestros de la India antigua, de nombres imperecederos, vivieron en el bosque. En la orilla umbría de algún río sagrado o de algún lago del Himalaya, hacían su altar de fuego, apacentaban su ganado y cultivaban el arroz silvestre y las frutas para su alimento. La naturaleza era su hogar y el de sus esposas y sus hijos; y en su seno meditaban sobre los problemas más hondos del alma, haciendo objeto de su vida la unidad del alma con toda la creación y la comunicación con el Ser supremo. Sus discípulos se congregaban a su alrededror y así recibían sus enseñanzas sobre la vida inmortal, en el lugar de la verdad, de la paz y del alma libre...

Hoy me ha llegado a mí también mi vez de soñar en aquella edad que se levanta por encima de todas las que le siguieron, con la majestad de su sencillez y su sabiduría de la vida pura.

Más adelante agrega lo siguiente:

el raudal de los ideales que nacieron en la cumbre de nuestro pasado y corrían ahora subterráneos por lo más hondo del suelo de la India: la sencillez de la vida, la claridad de visión espiritual, la pureza del corazón, la armonía con el universo, la conciencia de la personalidad infinita de toda la creación.

\section{Y continúa:}

...Me vine a vivir al santuario de Shantiniketan, fundado por mi padre, y poco a poco, se fueron reuniendo alrededor de mí, bajo la sombra de los árboles de saala 10 , muchachos de hogares distantes.

Esta concepción filosófica de la vida, en la que el ser humano se valora y es capaz de aprender porque es criatura divina y el conocimiento es un alimento para el alma, logró romper con las concepciones tradicionales europeas, inclusive indias, donde el castigo hacia el alumno era el único medio para que el niño aprendiese, y no la motivación y la alegría de entender sobre lo que le rodea. Como consecuencia de este pensamiento buscó un desarrollo pleno de la personalidad y el debido respeto, porque podían aprender en su escuela tanto las niñas como los niños, no había discriminaciones ni de género o nivel social, ya 
que se habitaba en casas familiares. Así el autor logró reunir a los jóvenes pobres provenientes de los pueblos cercanos, huérfanos, y algunos que eran rechazados en las escuelas tradicionales, inclusive por sus defectos físicos, puesto que la persona "infinita e individual”, según sus términos, tenía derecho a disfrutar de un medio propicio de educación para poder desarrollar sus facultades. Para ilustrar esto, la historia de Benod Behari Mukherjee es muy especial. Nació en 1904, en un suburbio de Calcuta, con serios defectos en la vista que, finalmente, lo dejaron ciego, cuando era un consagrado pintor. $\mathrm{Y}$ a pesar de su ceguera continuó realizando su obra artística.

Sus padres lo enviaron a Shantiniketan, a los trece años, puesto que en las escuelas tradicionales no era aceptado. Aquí en Bolpur recibió su educación en arte bajo la guía de Nandalal Bose ${ }^{11}$ y se quedó como profesor en el Departamento de Arte de la Universidad Vishva Bharati, en la que realizó casi toda su obra, como puede apreciarse en algunos murales que dejó en los edificios de la Universidad (Chen-Apuy 1984:275, 276).

En el siguiente párrafo nos describe el autor la llegada de muchos de esos niños y las condiciones en que llegaban:

A su llegada, la mayoría de los muchachos eran débiles de mente y de cuerpo. Como herencia fatal acusaban los estragos de la malaria y demás enfermedades tropicales. Su deformación mental era punto menos que intolerable; el brahmán poseía un orgullo despectivo, el no brahmán era digno de lástima como humillación consentida. (La escuela del poeta, pág. 286).

En ese mismo ensayo, "La escuela del poeta", enuncia sus razones personales y filosóficas del por qué de su decisión, y la explicación que da a las preguntas sobre este tema:

He deducido que el público exige una explicación de mi parte, por haberme atrevido a fundar una escuela, siendo poeta. Forzoso es admitir que el gusano de seda que hila y la mariposa que flota en el aire representan dos etapas distintas de la misma existencia.
El gusano de seda parece gozar de un crédito a favor en el Banco de la naturaleza, de acuerdo con la cantidad de labor realizada. Pero la mariposa carece de responsabilidad; en ella todo simboliza lo fútil y superfluo, y la danza grácil de sus alas parece acompasar su ingravidez. ¿Quizá se reúne, a la luz de un rayo de sol, con algún Rey del color que, ajeno a los libros de contabilidad, domina en cambio el difícil arte de la prodigalidad?

El poeta puede ser comparado a la inconsecuente mariposa. También él intenta convertir en poema los gayos colores de la creación. ¿Por qué iba a dejarse atar por el deber? ¿Por qué iba a rendir cuentas a los que valorarán su producción según criterios de utilidad? (pág. 275).

Y enuncia más adelante que si el ambiente ideal en donde crearon esos sabios de las Upanishadas era el bosque, la selva y que ha sido una firme creencia india el ideal de la Tapovana ${ }^{12}$ o lugar aislado en el bosque donde se retiraban estos hombres en la búsqueda de unión con el Espíritu Supremo y tratando de vivir con Él en todas partes, enseñanza que permite la creativa existencia humana, en pleno contacto con la naturaleza para lograr un ambiente sano y equilibrado donde logre el niño una libertad de espíritu y un aprendizaje completo no solo de los libros sino de la vida misma, un ideal vigente, hoy día, donde el cemento ahoga al joven que solo por medio de una pantalla trata de aprender cómo son los reinos naturales, pero este es un aprendizaje, no una vivencia. El modelo de su escuela lo toma de esta forma de vida que Tagore describe a continuación:

no eran gentes de cultura rudimentaria, sino buscadores de la verdad a cuyo culto se consagraban, en la pureza, pero no en el puritanismo; llevaban una vida sencilla pero no de mortificación. No eran fanáticos del celibato y vivían en contacto íntimo con sus contemporáneos y sus intereses mundanos, sin abogar por el celibato... No era ésta una filosofía negativa de renunciación. (La escuela del poeta, pág. 277).

En este párrafo se afirma en las últimas palabras que no era una renunciación, lo que quiere decir que necesariamente era una forma de vida que conllevaba la actuación como resultado de una vida sencilla y 
disfrute de todo; y así este ideal resumía a su vez la concepción del niño como un ser que nace del deseo divino, del amor y es naturalmente, por lo tanto, feliz y la educación debía promover su capacidad de aprender naturalmente y sin sufrimiento por el deseo mismo de hacerlo, como cuando los niños de su escuela deseaban aprender más inglés y le pidieron al maestro una hora más de clase diaria del idioma, como resultado de una experiencia vivida, a lo que el autor dice: ¡En cambio, yo recuerdo aún las ideas homicidas que acudian a mi mente infantil cuando veía llegar a mi profesor de inglés por el camino que conducía a casa! (La escuela del poeta, pág. 285).

Los jóvenes, a su vez, recibían las lecciones cuando era posible al aire libre, sobre todo los de primaria para lo cual la observancia del mundo que los rodeaba era muy importante para despertar el interés por la investigación de la ciencias naturales; las cuales no se enseñaban aisladas de las otras materias. También, bajo los árboles, se enseñaba la música y la pintura, lo mismo que se realizaban pequeñas representaciones teatrales, o sea, la creatividad sobre lo aprendido era múltiple y daba oportunidad a todos los alumnos de expresarse.

En cuanto a la formación moral, los alumnos aprendían formas de trabajo en conjunto donde todos se beneficiaran del trabajo de todos, con una vida sana y activa se estimuló capacidades que ellos mismos desconocían, puesto que vivían en la escuela, debían cocinar, limpiar, cuidar el jardín y los huertos, hacer sus tejidos y a arreglar sus habitaciones o prestar servicios de cualquier índole, aprendiendo la responsabilidad y la consciencia de que sus actos personales afectaban a los demás. Así desarrollaban con el aprendizaje formal su inteligencia y su capacidad creadora de manera equilibrada. Además de que consideraba que era más fácil educar a los niños si estos residían en el lugar.

Y concluye su ensayo diciendo que:

el subconsciente de los niños, al igual que los árboles, se nutre de la atmósfera circundante. Para ellos, el ambiente es mucho más importante que el reglamento y los métodos, los libros de texto y las clases.

Casi un siglo ha pasado desde que esta escuela se inició, sin embargo, estas palabras de Tagore siguen vigentes, en los estudios científicos modernos se habla de este tema, y se afirma en ellos que para que el ser humano se desarrolle a plenitud, es necesario un ambiente sano donde el niño puede entenderse con otros y a su vez, respetar diferencias de etnia, religión y cultura, y que el autor veía tan fuertemente arraigadas en la India de su entonces, y separaban al ser humano de sus iguales. Hoy más que nunca, estos ideales educativos son valiosos en un mundo donde las guerras fraticidas tienen un origen en la pretendida y errónea superioridad del color, el credo o cultura. Sobre este aspecto el autor, en el siguiente párrafo, nos dice:

Hoy en día parece como si se incapacitara la mente de los niños para entenderse con gentes de lengua y costumbres diferentes. El resultado es la hostilidad de unos con otros; la ignorancia es la peor forma de la ceguera contemporánea. (La escuela del poeta, pág. 288).

Ante esas palabras no podemos dejar de reflexionar y llegar a la conclusión de que su ideas son vigentes.

Luego agrega una crítica al sistema educativo cristiano de ese entonces, el cual en su exclusividad religiosa, lo hacía responsable de favorecer una actitud de desprecio hacia las etnias asiáticas y las religiones de su país, aspecto que justificaba la colonización y administración inglesa en la India, cuando agrega lo siguiente:

Hasta los misioneros cristianos contribuyen a mantener este desprecio por las razas y civilizaciones extranjeras. Animados por su sectarismo, y aunque preconizan la fraternidad humana, hacen uso de libros de texto escolar que corrompen las influenciables mentes juveniles. (La escuela del poeta, pág. 288).

Aunque es importante señalar que los misioneros cristianos también abogaron, en su momento, por la necesidad de abolir 
la sati o inmolación de la viuda, niña o no, ante la pira funeraria del esposo.

Comprendemos así que su ideal educativo más importante, era lograr que la educación enseñara la comprensión de otros pueblos y culturas a los niños. Integrar lo mejor de occidente y de oriente para buscar la universalidad en los ideales educativos del mundo.

Hay otros dos aspectos notorios en su pensamiento educativo, uno consistía en hacer un programa de actividades diario lo suficiente variado, para no obligar al niño a estar quieto, impasible; ya que como él afirmaba el niño es activo por naturaleza. El segundo aspecto consistía en que la educación debía impartirse en la lengua materna principalmente, no en una lengua extranjera, aspecto del que se hablará más adelante. En su ideal educativo se fundían tres valores: verdad, belleza, bondad; puesto que para él la belleza es necesariamente moral, y la moralidad debe unirse al espíritu de la belleza para que el hombre alcance la verdad (Tagore:1961, 23)13. Puesto que él pensaba que transformando a los niños y jóvenes se transformaba su patria, por tal razón Gandhi le puso el apelativo de "El gran centinela de la India”, además creía que la educación debía estar en constante relación con toda la vida económica, intelectual, estética, social y espiritual del mundo y agregaba lo siguiente:

Pues la verdadera educación significa darse cuenta a cada paso de cómo nuestro aprendizaje y nuestros conocimientos tienen una relación orgánica con nuestros alrededores. (Hacia el hombre universal pág. 203).

\section{La lengua materna y la lectura}

Además de lo señalado anteriormente, hay otros aspectos muy valiosos en la filosofía educativa de Tagore, uno de ellos se refiere a la enseñanza en la lengua materna y otro muy relacionado con el lenguaje es el de la lectura, especialmente la recreativa, la que llamaba el autor por diversión.
Anteriormente, en este acercamiento a la filosofía educativa, se había hablado de la imposición de la lengua inglesa como el idioma oficial para la enseñanza de toda la India, junto con la educación oficial inglesa en todas las escuelas de la India. Tagore propuso una enseñanza para los indios en sus lenguas maternas y así, en su escuela, lleva a la práctica este ideal, haciendo de la lengua bengalí el instrumento básico de conocimiento, puesto que su escuela se estableció en la región de Bengala, aunque no consideraba del todo necesario descuidar el inglés. Era la búsqueda de encontrar una nueva forma de aprender para los jóvenes indios, no significaba rechazar el inglés del todo, puesto que ya tenía más de medio siglo de haberse impuesto en la India, sino de darles el instrumento para que los indios se identificaran con su cultura.

La enseñanza oficial en inglés se había consolidado con la llegada de los misioneros, en 1840, a la India, con fines pastorales, evangélicos y educativos. Crearon una red de colegios e instituciones filántropicas, especialmente médicas; fue una época en que se hicieron cristianos unos 7 millones de indios, sobre todo de las castas inferiores.

Esto podría significar que la educación en inglés pretendía unificar lingüísticamente a la India y así facilitar la administración; sin embargo, no fue una empresa fácil. Implicaba un cambio más profundo, era un pretender alejar a los indios de sus raíces, al hacerlo de sus lenguas maternas. Pero la India era mucho más de lo que los ingleses pensaron, tan solo la cantidad de idiomas con sus literaturas y culturas en general, cuyo modelo gramatical y estético había sido el sánscrito. Para entender esto, debemos aclarar que a la India, en época de Tagore y aún hoy, se le ha considerado un subcontinente lingüístico, ya que se hablan unas 27 lenguas indoarias modernas ${ }^{14}$ (a partir del año 1000 más o menos), junto con sus dialectos, y todas se derivan del sánscrito ${ }^{15}$. Esto sin contar las lenguas dravidias que son las del sur de la India. Hacen su 
aparición así las literaturas, y deben clasificarse en tres grandes conjuntos, en primer lugar: hindi, bengalí y marathi; en segundo lugar: oriya, panjabi, gujarati, asamés; y aparte, el urdu que no es otra cosa que una variante del hindi. Hay que tener en cuenta que estas son apenas unas cuantas de las treinta y tantas lenguas de la India, sin contar los dialectos. El sánscrito se seguía considerando la lengua "ideal" y en ella se siguió componiendo literariamente, influencia que se mantuvo en las lenguas dravidias. Por otro lado, la presencia del inglés crea un gran impacto cultural, como lo describe el gran sanscritista Renou (1965: 85-86) en el siguiente párrafo:

La situación cambia a veces bruscamente, en contacto con el inglés, desde comienzos del siglo XIX. Sin abandonar la antigua manera de composición, las literaturas se modernizan, se simplifican las lenguas y el estilo, y también las ideas toman un giro nuevo. Como ha dicho un conocido escritor bengalí, "con el inglés, la prosa llegó a la India y la rima dejó su lugar a la razón”.

A lo que agregamos que el cambio se dio, precisamente, al imponer la educación en el inglés, de esta manera se empieza la dominación cultural que sustentará la administrativa. Los ingleses y otros europeos, en el siglo XVIII, crean factorías en Asia, en la búsqueda de establecer comercio, como resultado de la industrialización del siglo XVII, que obligaba, aparentemente, a los países industrializados a buscar mercados más grandes para así vender lo que se producía en gran escala. Así se establece, en Calcuta, The East India Company, en 1770. La administración inglesa solo fue un paso posterior, ya que en la misma región de Bengala, competían otros países europeos que mantenían sus factorías. Poco a poco el gobierno inglés, en toda la India, se iba a convertir en una necesidad. Se sustituye el persa en los asuntos legales y administrativos por el inglés, así se comienza la unión de un subcontinente dividido por reinados hindúes y musulmanes con fuertes competencias lingüísticas. El dominio inglés se afianzó al no tener la India un concepto de nación, ni unidad religiosa, cultural o lingüística. Por esto los indios cultos pensaron, por primera vez, en tener una patria única.

La reforma educativa en la India, en la colonización inglesa, se inicia cuando se les solicita a los misioneros evangélicos que fuesen a encargarse de la educación en Calcuta, a partir de 1813, y así el Parlamento inglés obliga a la compañía The East India Company a dedicar una suma de dinero destinada a las instituciones de la India fundadas por misioneros. También gran cantidad de dinero fue destinado para estimular la educación en sánscrito, árabe, persa y otras lenguas asiáticas y por supuesto del inglés siguiendo el modelo de educación inglesa. Las clases altas de indios, en los inicios del siglo XIX, veían a las lenguas vernáculas con desprecio como en la Edad Media europea se pensaba en la superioridad del latín para expresarse o estudiar por encima de las lenguas romances que luego se convirtieron en el francés, español e italiano (Pitney 1968:194), lo que daba indicios de dos aspectos, por un lado, el desprecio por las lenguas indoarias medias como el bengalí, hindi y otras, lo que implicaba el negarse a escribir en ellas y desconocer su larga historia literaria y que se remontaba en el caso del bengalí hasta el siglo X y XI. Entonces los indios educados solo escribían en lengua inglesa y buscaban imitar los modelos europeos; y por otro lado es importante resaltar la admiración profunda por parte de los europeos cultos, hacia el sánscrito y la apertura de las Cátedras de Sánscrito en las principales universidades europeas, y su estudio e investigación llevó al nacimiento de la Filología comparada, de la Lingüística, las Religiones y Mitologías comparadas, etc.

Poco a poco así se convierte la educación inglesa en oficial y obligatoria, en el año de 1835, cuyo objetivo Lord Macaulay 16 explica muy bien con las siguientes palabras (Pitney 1968:194): 
We must do our best to form a class who may be interpreters between us and the millions whom we govern; a class of persons Indian in blood and colour, but English in taste, in opinions, in morals, and in intellect.

\section{Cuya traducción sería así:}

Nosotros debemos hacer lo mejor para formar una clase que pueda ser intérprete entre nosotros y los millones que gobernamos; una clase de indios en la sangre y el color de piel, pero ingleses en el gusto, opiniones, moral e intelecto.

La cita anterior es lo suficientemente clara para exponer la situación imperante en la India, y entender la visión sobre la educación de Tagore; pero es necesario explicar el por qué de la educación inglesa en la India. Como el autor nace en Calcuta, la ciudad en donde se establecen los ingleses y desde allí se gobernaba al resto del país, por tanto, es la que tuvo mayor influencia europea; pero también fue de donde partieron muchas de las reformas culturales indias como ya hemos explicado anteriormente.

¿Cómo buscó conciliar Tagore una educación inglesa con una educación india? El autor encontró la respuesta cuando creó su ideal educativo para todos los niveles de la educación. Por otro lado, hay que entender que la administración inglesa logra un verdadero impacto en la cultura india, los ingleses habían impuesto un gobierno extranjero, pero no buscaron asimilarse a los que "conquistaron" y siempre manifestaron, a excepción de unos pocos, una superioridad sobre los indios. Los indios que a su vez habían sido invadidos en diferentes ocasiones pero, aunque hubiese diferencias de cultura, religión, lenguas, estos pueblos se habían asimilado y se convirtieron en parte de la India, en el caso de los ingleses no.

Por su lado, la India era un mosaico de culturas, costumbres, lenguas, que para considerar una búsqueda de autoafirmación y de identidad nacional era necesario hacerlo desde un renacimiento de la lengua y en consecuencia de la cultura, también la necesidad de un movimiento que hiciese reformas sociales. Surge, así, el renacimiento cultural bengalí que tenía como objetivo el revalorizar lo nacional, lo indio y así se empieza a escribir en bengalí toda clase de literatura, inclusive periódicos y revistas; era un momento en que los indios de cualquier credo o cultura hacían una evalución de lo nuevo y de lo antiguo en la búsqueda de la formación de una nación. Tagore no se escapa de presentar sus respuestas a diferentes interrogantes y la educación era una de ellas por eso se atreve a plantear la necesidad de estudiar en los colegios en las lenguas maternas, puesto que para él era sumamente significativo identificarse con su nacionalidad. A diferencia de una educación extranjera que no tomaba en cuenta la lengua materna, inducía a los indios a pensar en una lengua extranjera alejada de toda realidad cotidiana, esto hacía que el ser humano en esa sociedad no se identificara con ella y a su vez, esa cultura lo rechazara. Era educar indios para ser extranjeros en su patria y al servicio de una cultura extraña e impositiva, porque tanto indios como ingleses no se integraron, solo en raras ocasiones.

Aparte del valor del dominio apropiado y paulatino de la lengua materna, que le facilita al joven el comprenderse a sí mismo, conocer quién se es y de dónde proviene, está un importante factor que Tagore denuncia: el inglés es diferente gramaticalmente al bengalí, lo que creaba un abismo entre lo que se aprendía de lo que se utilizaba cotidianamente. Los libros de texto y de lectura ingleses creaban dificultades, según afirmaba y evitaban que el niño imaginara, puesto que no provocaba en él imágenes que evocasen lo conocido, lo que le era familiar, sino que eran lecturas alejadas de la realidad bengalí, empezando por las diferencias climáticas, a lo que agrega:

Para ellos la lectura de estos libros es como andar a tientas en la obscuridad. (Las vicisitudes de la educación, pág. 55). 
Es una clara definición de la importancia de la lectura para hacer que el niño se vuelva creativo a través de la imaginación; y aquí entra la importancia que le dio a la lectura, sobre todo, a la recreativa como expresa en el siguiente párrafo:

El niño necesita muchos libros de recreo para poder asimilar convenientemente un solo libro de texto. Cuando un muchacho lee algo por su gusto, aumenta imperceptiblemente su capacidad de lectura, y fortalece en forma fácil y natural sus facultades de comprensión, asimilación y retención. (Las vicisitudes de la educación, pág. 50).

Así describe dos aspectos importantísimos, uno y el más importante que nos habla de que el joven para poder estudiar un libro de texto tiene que haber leído muchos libros de recreación, o sea haber adquirido suficiente lenguaje para entender un lenguaje especializado. Lo que quiere decir es que la edad ideal para que el joven tenga suficiente vocabulario asimilado y aprehendido, es la niñez, y no solamente que lo reciba del aprendizaje de su lengua materna sino que lo haga con libros amenos. Tagore presentó una de las bases para la comprensión de lectura y la adquisición de cultura en los colegios, un asunto de actualidad en el mundo entero. Quizá aquí haya una posible respuesta que nos la ha dado Tagore, el niño y el adolescente deben leer por diversión buenos libros que despierten su imaginación para que la lectura no sea una obligación o un tedio.

Ya en su ensayo Las vicisitudes de la educación, nuevamente, planteó su preocupación por la lectura y el papel que cumple en la enseñanza durante los años de niñez o de adolescencia y así expresa lo siguente:

Leer sin pensar es como acumular materiales de construcción sin emplearlos para construir. (Pág. 53).

Así Tagore se propuso en su escuela, que durante la vida del niño se debe desarrollar su capacidad de lenguaje, junto con la imaginación, y la lectura apropiada que lo promueva; por tal razón el joven adolescente, sin estos dos elementos, no podrá aprender sin sufrir grandes dificultades. Otro aspecto que nos deja muy claro, es que el niño aprende asociando lo que está en los libros no como conocimientos muertos puesto que los relaciona con su mundo, de esta manera hay interacción entre el conocimiento de la escuela con el de su mundo particular, que redunda en la utilización de textos que le muestren su entorno y no mundos extraños a él.

Así vemos aspectos educativos donde la niñez tiene valores, virtudes que lo harán servir y servirse de una sociedad que se beneficiará del desarrollo de todas las posibilidades de la personalidad, dentro del marco de la naturaleza, integrándose en ella. También el "poeta" sentó las bases para un nuevo ideal filosófico, en donde el maestro "vive" el conocimiento, donde no siente que lo que enseña no es la vida misma. Son famosas sus siguientes palabras:

Un maestro nunca puede enseñar verdaderamente a menos que él esté todavía aprendiendo... Más adelante afirma: La verdad no solo debe informar sino que también debe inspirar. Si la inspiración muere y la información se acumula, entonces la verdad pierde su infinitud. (El maestro ideal).

\section{Vishva Bharati, la universidad}

Al fundar la universidad Vishva Bharati a inicios del siglo XIX; ya en 1857, en tres ciudades indias: Bombay, Madras y Calcuta, comienzan las universidades a funcionar en la India, cuyo modelo era la Universidad de London, así estos centros de estudio superior se consideraban "afiliadas" al modelo de educación superior inglés. Si observamos la situación de la educación superior en la India, diríamos que ésta continuaba con la necesidad de los colonizadores de sustentar su gobierno inglés; de esta manera el modelo inglés era el "ideal" educativo desde la primeros años hasta la universidad. Así realmente, se cumplía a la perfección las palabras de Lord Macaulay de educar indios-ingleses. 
Tagore, a pesar de que fue enviado a estudiar abogacía a Inglaterra, y como ya sabemos nunca sintió desprecio por lo inglés, más bien pensaba que era importante el aprender de ellos conservando lo propio, las raíces de la cultura india; promovió una universidad cuyo ideal se resumía en estas palabras en sánscrito "yatra visvan bharati eka nidam”, cuyo significado es el siguiente:

donde el mundo entero encuentra su nido;

con estas palabras nos habla de uno de sus objetivos al fundar esta universidad, el hacerla internacional. Su ensayo Universidad hin$d u ́$ se inicia con las siguientes palabras, que nos aclaran también esta finalidad:

En nuestros días las comunicaciones entre los pueblos del mundo aumentan y los contactos internacionales se multiplican. Este hecho bien pudiera hacernos pensar que ha llegado el momento de enterrar en la unión las diferencias raciales y nacionales (pág. 145).

La búsqueda de lo humano, de ese "algo" que las personas de diferentes nacionalidades tienen en común; el comprender las culturas, el respetar las diferencias de credo y costumbres. Era provocar un encuentro entre Oriente y Occidente. Entre los otros objetivos estaban, por un lado, el conocer la mente humana desde la dimensión de la verdad, motivando de esta manera la investigación; y en el otro aspecto promover la paz y la concordia entre los pueblos. Y sobre todo, hacer de la India, el lugar donde se ofreciera la hospitalidad y su cultura en beneficio de los otros.

En su universidad buscó impartir cátedras de todas las religiones y se invitó a grandes eruditos, tanto de Oriente como de Occidente, a enseñar y a cooperar con otros pensadores sin importar posibles antagonismos de raza, nacionalidad, credo o casta y en nombre de un ser supremo único; se motivó a impartir cursos sobre todo lo conocido: historia, ciencias, artes, literaturas. Era, en todos los aspectos una universidad internacional.
Con las siguientes palabras del citado ensayo, Tagore define, claramente, lo que él consideraba debía ser la universidad:

Solo la Universidad ofrece la posibilidad de un libre desarrollo y activa la inteligencia haciendo que el espíritu adquiera conciencia de sí mismo. Alcanzada esta conciencia, automáticamente se comenzará a progresar rompiendo el orden de ideas estereotipado. (Pág. 155).

En ocasiones, cuando el mundo actual necesita una universidad más comprometida con la paz, el conocimiento y respeto de las otras culturas y sobre todo el poner el pensamiento traducido como verdad al servicio del hombre y sus necesidades, el ideal de Tagore adquiere absoluta vigencia. Actualmente, Bolpur sigue siendo el centro donde acuden de todas partes del mundo a recibir lo que pretendió su fundador:

donde el mundo encuentre su nido.

\section{Conclusiones}

El poeta que se convirtió en maestro, en promotor de unos ideales educativos novedosos y a su vez apegados a la tradición más antigua de la India; el hombre amoroso que escribía obras de teatro, asignándose un papel, para representarlas con los alumnos de su escuela y así promover la comprensión de la vida misma; el artista que pintaba los escenarios y componía la música de esas mismas obras y con melodiosa voz participaba en ellas asignándose el papel del anciano. En fin, el ser humano genial que dejó una hermosa obra literaria, cuyas ideas tan indias son, a su vez, universales y que rompen la barrera del tiempo y el espacio. Fue también el educador.

Un genio, pero también un ser humano comprometido con sus ideales sobre la educación de los jóvenes de su patria, y que sabiamente experimentó con el mundo cercano a él. El maestro que buscó fortalecer el idioma materno y así integrar al joven con 
sus raíces, pero más que eso, convertirlo en un ser creativo y comprometido con su entorno social. A su vez, hacer sentir al joven que la naturaleza no estaba alejada de él y de ella también podía aprender la vida y la creación divina.

El Tagore deseoso de establecer, en su escuela primero y luego en su universidad, un valioso diálogo entre dos mundos aparentemente distantes: oriente y occidente, adelantándose así a las necesidades que el mundo moderno requiere. Por otro lado, la concepción del niño que promovió lleno de dignidad, y que debe ser educado con el pleno derecho de ser respetado y de aprender a respetar las dignidades de los otros con quienes comparte.

En fin, sus ideales educativos siguen actuales, y han sido inspiradores de diferentes modelos educativos modernos. $\mathrm{Y}$ aunque Tagore, el poeta, nos ha hecho imaginar con un mundo lejano al nuestro, al conocer sus ideales educativos no podemos dejar de reflexionar sobre lo que podemos aportar con ellos a nuestro modelo educativo, ya que su filosofía tiene un fuerte arraigo en los valores espirituales, en la capacidad creadora, en la superación, en la igualdad y libertad del ser humano; pero sobre todo, la firme creencia en que la educación con verdaderos valores permitirá la comprensión y la convivencia pacífica en el mundo.

\section{Notas}

1. Es importante aclarar que el autor publicó la mayoría de su obra literaria en su lengua materna el bengalí, pero cuando quería mayor difusión de sus ideas lo hizo en inglés.

2. Era, a su vez, hijo del Príncipe (Raja) Dwarkanath, famoso por su riqueza y posición social, quien junto con Ram Mohum Roy (1772-1833) fundaron la Brahmo Samaj, que fue la primera organización moderna de la India dedicada a las reformas sociales y religiosas.

3. Entre los hindúes es la casta (jati) más alta.

4. La India ha tenido muchas lenguas, dialectos; hoy día, existen más de 35 lenguas con sus dialectos y no todas derivadas del sánscrito. Actualmente, el hindi y el inglés son las lenguas oficiales.

5. El término en sánscrito es bhakti o bhakti yoga: es el hombre cuya existencia gira alrededor de la devoción a un dios, y expresa su amor a esa deidad a través de su vida.

6. De la Religión del Hombre, página 213.

7. Op. cit., página 216.

8. Sua dharma: se podría decir que es la naturaleza propia de cada individuo, las posibilidades para desarrollar con que nace. En Tagore fue característico la bhakti o lo devocional a la divinidad.

9. La palabra Upanishada significa: upa: cerca; ni: abajo y la raíz SAD: sentarse; o sea, el alumno que se sienta a los pies del maestro para aprender. Se podría hablar de que los diálogos upanishádicos hacen su aparición en el siglo VIII a. C.

10. Es un árbol gigantesco denominado saala parecido a la teca, cuyo nombre genérico es $\mathrm{Va}$ tica robusta (MacDonnell, 1979:348).

11. Reconocido artista de la India que estuvo bajo la protección de Abanindranath Tagore, sobrino del poeta y que luego junto con éste, se convirtieron en colaboradores de Tagore en sus centros educativos.

12. Tapovana, palabra compuesta de tapas: calor, fuego, ascetismo y de vana: bosque.

13. Proviene del ensayo "La escuela del poeta" que se encuentra en Hacia el hombre universal.

14. Actualmente, el hindi es la lengua oficial junto con el inglés; sin embargo, sigue siendo una "torre de Babel".

15. El sánscrito es la lengua clásica de la India, que llegó con las tribus indoeuropeas en el segundo milenio antes de Cristo, sus primeros textos son los Vedas y se remontan a esta época.

16. Lord Macaulay era ensayista y miembro del Consejo Ejecutivo del Gobernador General de la India, y escribe un memorandum, del que proviene la cita, con el que da razones para la legalización de la educación inglesa en la India. 


\section{Referencias bibliográficas}

Chakravarty, Amiya. A Tagore reader. The Macmillan Company, New York, 1961.

Chen Apuy, Hilda. Nacionalismo y arte en la India contemporánea. Revista de Estudios de Asia y África \# 60. El Colegio de México, México, 1984.

Dimock, E.C. The literatures of India. The University of Chicago Press, Chicago, 1974.

Kripalani, K. Modern Indian Literature, a panoramic glimpse. Charles E. Turttle Co. Tokyo, 1971.

Hiranmay, Banerjee. Rabindranath Tagore. Iskylark Printers, New Delhi, 1981.

MacDonnell, Arthur. A Practical Sanskrit Dictionary. Oxford University Press, Great Britain, 1979.
Renou, Louis. Las literaturas de la India. Eudeba Editorial Universitaria, Buenos Aires, 1965.

Tagore, Rabindranath. Morada de Paz. Editorial Losada, S.A. Buenos Aires, 1948. La escuela del Papagayo. Editorial Cervantes, Barcelona, 1928.

Hacia el hombre universal. Editorial Porrúa, 1961. La religión del hombre. Editorial Aguilar, Argentina, 1968.

Pieczynska E. Tagore, educador. Imprenta helénica, Madrid, 1925.

Pitney, Beatrice. India. A world in transition. Praeger Publishers, New York, 1973.

Zimmer, Heinrich. Filosofías de la India. Eudeba Editorial Universitaria de Buenos Aires, Buenos Aires, 1965. 